\title{
$S H$ TRAVEL TIMES AND LATERAL HETEROGENEITIES IN THE LOWER MANTLE
}

By Mansour Niazi*

\section{ABSTRACT}

The horizontal long-period seismograms of two shallow earthquakes in Turkey and Iran recorded in selected azimuths are combined for travel-time studies of the $S H$ wave beyond the angular distance of $40^{\circ}$. The observed travel times along two profiles which sample the deep mantle in the vicinity of Iceland and the North Pole show monotonically increasing differences beyond $65^{\circ}$, indicating lateral heterogeneity in the lower mantle. The travel-time difference becomes as large as $7 \mathrm{sec}$ at $95^{\circ}$, implying a variation as much as $0.06 \mathrm{~km} / \mathrm{sec}$, or about 1 per cent, in the shear-wave velocity near $2,500 \mathrm{~km}$ depth. Inversion of observations, adjusted to surface foci, results in an average lower mantle structure with lower shear velocities than those given by Jeffreys. The difference exceeds $0.1 \mathrm{~km} / \mathrm{sec}$ at the core boundary.

The arrival time and signature of $S$ waves recorded in Greenland show anomalous features which may be related to deep seated anomalous zones associated with the Mid-Atlantic Ridge system.

\section{INTRODUCTION}

Seismic body waves have provided, in the most direct manner, important information concerning the structure of the Earth's interior. Application of new techniques, notably the direct measurement of $d t / d \Delta$ of the travel-time curve across arrays, have proved successful in delineating the $P$-wave structural details (Niazi and Anderson, 1965; Johnson, 1967 and 1969; Kanamori, 1967; Toksöz et al., 1967; Corbishley, 1970; Enahatollah, 1972) but have met with only limited success in shear-wave studies (Fairborn, 1969; Kovach and Robinson, 1969; Robinson and Kovach, 1972).

There are a number of difficulties in studies of the $S$ phase which interfere with accurate determination of $d t / d \Delta$. One of the difficulties is related to the inherent ambiguity in the identification of this phase. Being a late arrival, the $S$ wave is often contaminated by the $P$-wave coda. $S$ to $P$ conversion at a multitude of boundaries across which seismic waves are transmitted, or against which they are reflected, generate precursors to this phase. Some of the precursors arrive several seconds ahead of $S$ and, thus, when mistaken for $S$, may lead to the scatter of observations which ultimately introduces bias in favor of higher estimations of shear-wave velocities. Lomnitz (1971) discusses another source of such bias due to lateral heterogeneities in the transmission path. When correctly identified, such precursors may provide valuable information regarding the depth and the nature of the boundary at which they originate. Examples may be found in studies by Cook et al. (1962), Båth and Stefansson (1966), Pachadzhanova (1962), and Smith, (1970). Further difficulties, related to lower-frequency content and a higher degree of lateral variations of shear velocities relative to compressional velocities, tend to reduce the coherency of $S$ arrivals across array elements.

That the question of the variation of shear-wave velocities in the mantle may still be far from resolved can be noticed from the comparison of the results of recent studies reported by Cleary (1969), Bolt et al. (1970), Hales and Roberts (1970), Robinson and Kovach (1972), Fairborn (1969), Mitchell and Helmberger (1973), and Jordan and

*Present address: University of Mashad, Mashad, Iran. 
Anderson (1973). While the first four reports have suggested a decrease in the shear-wave velocities in the several hundred kilometers in the lowermost region of the mantle, Mitchell and Helmberger's conclusions require a 20-to-100-km thick layer of high $S$ velocity at the base of the mantle. Jordan and Anderson (1973), on the other hand, prefer a small reduction from Jeffreys' model (Bullen, 1963) throughout most of the mantle in order to satisfy the observed periods of the Earth's free oscillations and differential travel times.

Obviously, these apparently diverging views concerning the shear-wave structure of the mantle, particularly that of the lower mantle, call for further investigation. Furthermore, there is growing evidence (Phinney and Alexander, 1969; Davies and Sheppard, 1972; Kanasewich et al., 1973; Julian and Sengupta, 1973) that gross lateral variations in the lower mantle cannot be ruled out. Observed $S$ arrivals at epicentral distances short of the shadow boundary, which should provide information concerning the shear-wave velocity variations at the base of the mantle are, however, generally contaminated by phases such as $S c S, S K S, S K K S$. In the present study, the horizontally polarized component $(S H)$ of $S$ is studied; by proper rotation of the station coordinates, we have attempted to overcome the problems of $S K S$ contamination and $P$ to $S$ conversions.

The $S H$ arrivals of two shallow continental earthquakes recorded at stations within three azimuthal, windows are analyzed. The hypocenters and other pertinent information of these earthquakes as determined by the International Seismological Center (ISC) are given in Table 1.

TABLE 1

\begin{tabular}{lcl} 
Hypocentral & $\begin{array}{c}\text { Parameters of THE } \\
\text { Determined By ISC }\end{array}$ & EarthQuakes \\
& \multicolumn{2}{c}{ AS } \\
\hline \multicolumn{1}{c}{ Parameters } & Earthquake 1 & \multicolumn{1}{c}{ Earthquake 2 } \\
\hline Location & Western Turkey & Eastern Iran \\
Date & July 22, 1967 & August 31, 1968 \\
Origin time & $\mathbf{1 6 : 5 6 : 5 8 . 0 \pm 0 . 1 5}$ & $10: 47: 41.3 \pm 0.28$ \\
N. latitude & $40^{\circ} .67 \pm 0.027$ & $34^{\circ} .15 \pm 0.053$ \\
E. longitude & $30.69^{\circ} \pm 0.023$ & $59.01^{\circ} \pm 0.045$ \\
Depth (km) & $33 \pm 3.3$ & $25 \pm 0.80$ \\
\hline
\end{tabular}

The surface-wave magnitudes assigned to these earthquakes are 7.1 and 7.2 , respectively. Both involve nearly $80 \mathrm{~km}$ of surface faulting (Ambraseys and Zatopek, 1969; Ambraseys and Tchalenko, 1969). Faulting in both cases is dominantly strike-slip, the sense of motion being right-lateral for earthquake 1 and left-lateral for earthquake 2 . Focal mechanisms solutions obtained from the polarity of $P$-wave first motion are consistent with the field observations (Niazi, 1969; McKenzie, 1972) suggesting a nearvertical fault plane striking nearly $\mathrm{E}-\mathrm{W}$.

\section{Travel-Time Observations}

The seismograms consist of those recorded at distances 30 to $110^{\circ}$ by the WWSS Network in Europe, North America, and Africa and by the Canadian Network, as shown in Figure 1. Although a number of short-period $(S P)$ records were used to clarify specific points such as focal depth of earthquake 1 (see also the record section shown in Figure 4), all of the travel times were read off the long-period ( $L P$ ) records. In all cases, whenever the station-to-epicenter azimuth deviation from the instrumental orientation exceeded $20^{\circ}$, an appropriate rotation was applied to the digitized horizontal traces in order to resolve the motion into its transverse and longitudinal components. 
Since the $S H$ phase generally had an impulsive onset, the reading errors are not expected to exceed $2 \mathrm{sec}$. The measured travel times, corrected for ellipticity (Bullen, 1937), are plotted in Figure 2 (see also Table 2).

The $S H$ travel times and amplitudes for earthquake 2 at distances $91^{\circ}$ to $113^{\circ}$ to the north of the epicenter have been previously studied by Bolt et al. (1970). Their adopted hypocenter solution was $t_{o}=10^{h} 47^{m} 41.0^{s}, 34.10^{\circ} \mathrm{N}, 58.96^{\circ} \mathrm{E}, 14.3 \mathrm{~km}$ depth. Except for a nearly $10-\mathrm{km}$ difference in focal depth, this agrees with ISC. The USCGS estimation for depth is $13 \mathrm{~km}$. In this study, a 14-km focal depth is adopted for earthquake 2 . The discrepancy between focal depth estimations of earthquake 1 by USCGS ( $4 \mathrm{~km}$ ) and ISC $(33 \pm 3.3 \mathrm{~km})$ is larger. Considering the observed surface faulting, the hypocenter probably lies in the crust. The short-period E-W (transverse) record of this earthquake at WIN $\left(\Delta=64.2^{\circ}\right)$ shows a distinct second arrival about $9 \mathrm{sec}$ after $S$. A likely explanation

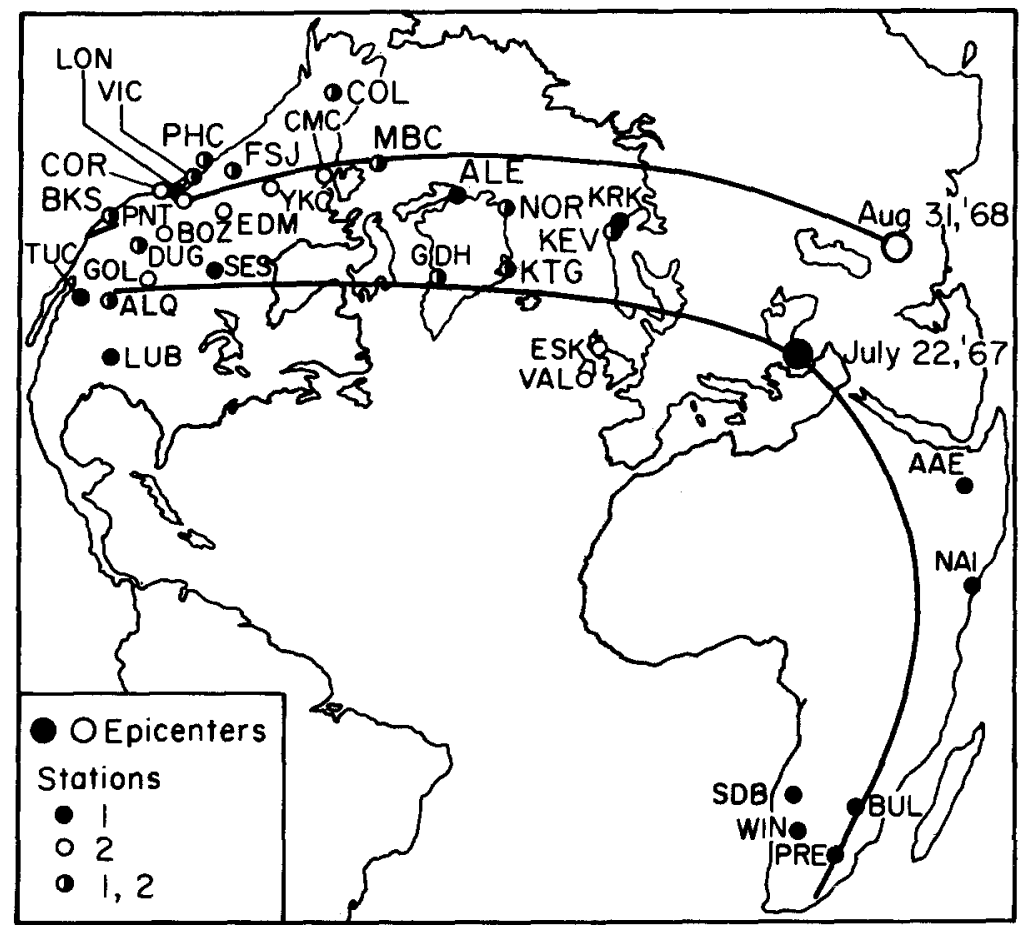

FIG. 1. Distribution of the recording stations with respect to the epicenters. The three great circle paths represent approximately the three profiles along which the lower mantle structure is sampled. Only the data recorded at the stations in western North America are pertinent to the velocity structure in the lowermost $1,000 \mathrm{~km}$ of the mantle.

for the second arrival is surface reflection near the hypocenter $(s S)$. This would correspond to a focal depth of about $18 \mathrm{~km}$ according to the $J-B$ tables. Application of the same procedure to the N-S (radial) component of the $S P$ record written at COL $(\Delta=74.8)$ leads to a focal depth of $23 \mathrm{~km}$. The cubic polynomials (labeled 1 and 2 in Figure 2) fitted to the observed travel times of the individual earthquakes are almost parallel to a distance of $65^{\circ}$. To avoid triplications associated with the upper mantle discontinuities (for example, see Nuttli, 1969), a comparison of the observed times is made in the distance range of $50^{\circ}$ to $65^{\circ}$. It was found that the $S H$ arrivals of earthquake 2 on the average showed a 1.9-sec delay in this range. Having been influenced by the structural differences in the transmission paths and possible errors in the computed origin times, 
this difference in itself may be insignificant. However, it happens that a nearly 2-sec difference in arrival times also suggests that earthquake 1 may be deeper than 2 by as much as 6 to $7 \mathrm{~km}$ (it should be noted that some of the European transmission paths in this distance range cross).

Based on the foregoing arguments, a focal depth of $21 \mathrm{~km}$ is adopted here for earthquake 1. Depth corrections of 6 and $4 \mathrm{sec}$, respectively, are applied to the observed travel times in order to convert them to surface travel times. The cubic polynomials fitted to the two sets of the reduced and corrected travel times now practically overlap at distances of $40^{\circ}$ to $65^{\circ}$. However, at larger distances, the two sets of data show monotonically increasing differences, reaching $7 \mathrm{sec}$ at $95^{\circ}$.

It should be noted that the adoption of the 4-km depth, assigned to earthquake 1 by USCGS, would have increased this difference to $12 \mathrm{sec}$, while the adoption of ISC depth $(33 \mathrm{~km})$ would have reduced it to $4 \mathrm{sec}$ at the expense of introducing discrepancies with opposite signs of about $3 \mathrm{sec}$ at $40^{\circ}$ to $65^{\circ}$ distances.

Curve 3 of Figure 2 is a third-degree polynomial fit to the combined data points, corrected to zero depth. The standard error of estimate for the fit is $2.9 \mathrm{sec}$ and has the following form, at $\Delta>30^{\circ}$

$$
T(\Delta)=128.7+200.43(\Delta / 10)-6.585(\Delta / 10)^{2}+0.0590(\Delta / 10)^{3} .
$$

Before discussing the implications of the observed travel-time differences at large distances, several points need to be made. First, the signature of the $S H$ arrivals of earthquake 2 at NOR, KTG, and GDH appears peculiar. In contrast to the sharp onsets of this phase elsewhere, they begin with a long-period emergent shoulder, the main signal corresponding to the $S H$ pulse as observed at other stations arriving some 5 to 12 sec late. The anomaly at KTG (see insert of Figure 2 ) is particularly conspicuous. Despite the signature difference, the early arrivals are in better agreement with the rest of the observations. Although their arrival times have not been analyzed, the late onsets are also shown in Figure 2 with dissected hollow circles.

The three stations with anomalous recording are located in Greenland, at epicentral distances of $54^{\circ}$ to $66^{\circ}$ corresponding to penetration depths of 1,300 to $1,650 \mathrm{~km}$. Several observations of anomalous changes in the $P$ velocity or its gradients at these depths have been reported (Chinnery and Toksöz, 1967; Hales et al., 1968; Johnson, 1969; Corbinshley, 1970; Vinnik et al., 1972; Enayatollah, 1972), which may cause triplication of the travel-time curve at the distances under consideration. However, some of the five available records of earthquake 1 in this distance range, SDB, BUL, WIN, PRE in Africa, and $\mathrm{MBC}$ in the Canadian Arctic, fail to exhibit this feature. Instead; the same three stations, while covering shorter epicentral distances, $40^{\circ}$ to $50^{\circ}$ for earthquake 1 , have unidentified precursors to the main $S$ phase. Considering that the ray paths to these stations approach from the east, it is conceivable that regional effects, perhaps related to the Mid-Atlantic Ridge, are involved. Passage of the seismic ray through a medium of low $Q$ with dimensions as large as several wavelengths may provide a mechanism. The more energetic signal, in this case, may arrive via longer paths.

The second point is the sharp reduction in the strength of the $S H$ signal on the $L P$ records written at LUB and ALQ at epicentral distances of $94.1^{\circ}$ and $95.0^{\circ}$, respectively, and the extreme difficulty in observing the signal at UNM, $\Delta=104.3^{\circ}$. This is in contrast to the strong arrivals observed at the stations recording earthquake 2 at distances greater than $110^{\circ}$ to the north of epicenter (examples are published in Bolt et al., 1970). The presumed differences in focal mechanisms do not seem to be sufficient to explain the observed difference in the rate of decrease of signal strength with distance. Computed $S H$ amplitudes between $75^{\circ}$ and $95^{\circ}$ for the mechanism given by McKenzie (1972), 
predict 23 per cent reduction along $325^{\circ}$ azimuth for earthquake 1 as against 30 per cent along $360^{\circ}$ azimuth for the earthquake 2 mechanism (Niazi, 1969). Also, contrary to the high diminution rate of the observed $S H$ amplitude at LUB and ALQ, the record of earthquake 1 at KIP, $\Delta=117.7^{\circ}, A z=9^{\circ}$, registered a relatively strong $S H$ motion. This arrival is also plotted in Figure 2 but is not used in the analysis.

TABLE 2

Observed $S H$ Travel Times and Their Residuals from $\boldsymbol{J}$ - $\boldsymbol{B}$ Tables

\begin{tabular}{|c|c|c|c|c|c|c|}
\hline \multirow{2}{*}{ Earthquake } & \multirow{2}{*}{ Station } & \multirow{2}{*}{$\begin{array}{l}\text { Distance } \\
\text { (deg) }\end{array}$} & \multirow{2}{*}{$\underset{\text { (deg) }}{\text { Azimuth }}$} & \multicolumn{2}{|c|}{$\begin{array}{c}\text { Adjusted } \\
\text { Travel time* }\end{array}$} & \multirow{2}{*}{$\begin{array}{c}t-t J-B \\
(\mathrm{sec})\end{array}$} \\
\hline & & & & $M$ & $S$ & \\
\hline 1 & KRK & 29.1 & 359.6 & 10 & 53.4 & -2.8 \\
\hline 1 & KEV & 29.2 & 357.4 & 11 & 01.4 & 3.6 \\
\hline 1 & $\mathrm{AAE}$ & 32.3 & 165.0 & 11 & 53.9 & 7.3 \\
\hline 2 & KEV & 39.8 & 343.2 & 13 & 46.0 & 3.8 \\
\hline 1 & KTG & 39.9 & 335.3 & 13 & 49.1 & 5.4 \\
\hline 1 & NAI & 42.1 & 170,9 & 14 & 21.3 & 5.5 \\
\hline 1 & NOR & 44.1 & 351.1 & 14 & 49.0 & 3.9 \\
\hline 2 & ESK & 47.2 & 316.5 & 15 & 32.3 & 2.8 \\
\hline 1 & ALE & 50.3 & 350.2 & 16 & 17.6 & 4.2 \\
\hline 1 & $\mathrm{GDH}$ & 50.7 & 332.7 & 16 & 23.9 & 6.1 \\
\hline 2 & VAL & 51.6 & 312.4 & 16 & 40.7 & 9.4 \\
\hline 2 & NOR & 54.4 & 349.9 & 17 & 10.3 & 1.7 \\
\hline 2 & $\mathrm{KTG}$ & 55.3 & 336.1 & 17 & 23.7 & 3.0 \\
\hline 1 & SDB & 57.5 & 199.7 & 17 & 52.5 & 1.8 \\
\hline 1 & BUL & 60.5 & 182.2 & 18 & 32.8 & 3.4 \\
\hline 1 & $\mathrm{MBC}$ & 61.8 & 352.2 & 18 & 51.1 & 5.5 \\
\hline 1 & WIN & 64.2 & 194.0 & 19 & 19.4 & 4.1 \\
\hline 2 & GDH & 65.9 & 338.9 & 19 & 41.8 & 5.1 \\
\hline 1 & PRE & 66.1 & 182.5 & 19 & 44.0 & 4.7 \\
\hline 1 & $\mathrm{CMC}$ & 68.8 & 346.8 & 20 & 13.2 & 2.0 \\
\hline 2 & $\mathrm{MBC}$ & 69.9 & 359.6 & 20 & 27.2 & 2.5 \\
\hline 1 & $\mathrm{COL}$ & 74.8 & 359.3 & 21 & 26.4 & 6.4 \\
\hline 2 & $\mathrm{COL}$ & 79.1 & 11.3 & 22 & 16.3 & 8.9 \\
\hline 1 & EDM & 81.5 & 339.1 & 22 & 37.5 & 5.9 \\
\hline 1 & FSJ & 82.9 & 345.6 & 22 & 52.9 & 7.5 \\
\hline 2 & YKC & 83.6 & 357.0 & 23 & 03.8 & 10.7 \\
\hline 1 & $\mathrm{PHC}$ & 87.0 & 346.3 & 23 & 34.3 & 7.6 \\
\hline 1 & VIC & 88.3 & 343.1 & 23 & 41.3 & 2.6 \\
\hline 1 & LON & 89.6 & 341.5 & 23 & 56.3 & 5.7 \\
\hline 1 & GOL & 90.5 & 327.6 & 24 & 08.1 & 8.7 \\
\hline 2 & FSJ & 91.8 & 1.9 & 24 & 19.0 & 8.6 \\
\hline 1 & DUG & 92.9 & 332.9 & 24 & 28.2 & 7.8 \\
\hline 1 & LUB & 94.1 & 321.9 & 24 & 32.0 & 1.2 \\
\hline 1 & ALQ & 95.0 & 325.9 & 24 & 50.9 & 12.3 \\
\hline 2 & $\mathrm{PHC}$ & 95.4 & 4.1 & 24 & 58.0 & 16.6 \\
\hline 2 & PNT & 96.9 & 359.1 & 25 & 07.0 & 12.2 \\
\hline 2 & VIC & 97.7 & 1.6 & 25 & 16.0 & 14.7 \\
\hline 1 & BKS & 98.0 & 338.7 & 25 & 11.9 & 8.3 \\
\hline 1 & TUC & 99.1 & 328.0 & 25 & 31.5 & 18.4 \\
\hline 2 & COR & 101.7 & 1.7 & 25 & 47.0 & 13.7 \\
\hline 1 & UNM & 104.3 & 312 & $(26$ & $04.5)$ & 8.3 \\
\hline 2 & DUG & 105.7 & 353.5 & 26 & 23.0 & 15.2 \\
\hline 2 & BKS & 108.4 & 1.0 & 26 & 44.0 & \\
\hline 2 & ALQ & 110.0 & 347.3 & 26 & 55.7 & \\
\hline
\end{tabular}

*Travel times are corrected for ellipticity of the Earth and are adjusted to surface focus. 


\section{InVERSION OF THE TraVEL-Time Data}

In Figure 2, the curves designated IN1(33), IN2, and CIT11GBX show the transmission times of shear waves in the upper mantle for the models suggested by Ibrahim and Nuttli (1967), Nuttli (1969), and Julian and Anderson (1968), respectively. Slight modifications have been introduced in the CIT11GB model (very small velocity gradients between depths of 170 to $350 \mathrm{~km}$ and 460 to 650 , see Table 3 ). The two $x$ 's at nearly $29^{\circ}$ distance (Figure 2) are very energetic arrivals observed on the horizontal $S P$ records written at KRK and KEV. They are presumably late arrivals caused by discontinuities in the structure of the upper mantle. It appears that these short-period arrivals offer a better agreement with IN2 travel-time curves (IN1(33) is different from IN2, principally, in an assumed $33-\mathrm{km}$ depth of source). However, when these readings are corrected for the accepted $21-\mathrm{km}$ depth of source, the agreement no longer holds. Therefore, they may be related to other branches of the travel-time curve.

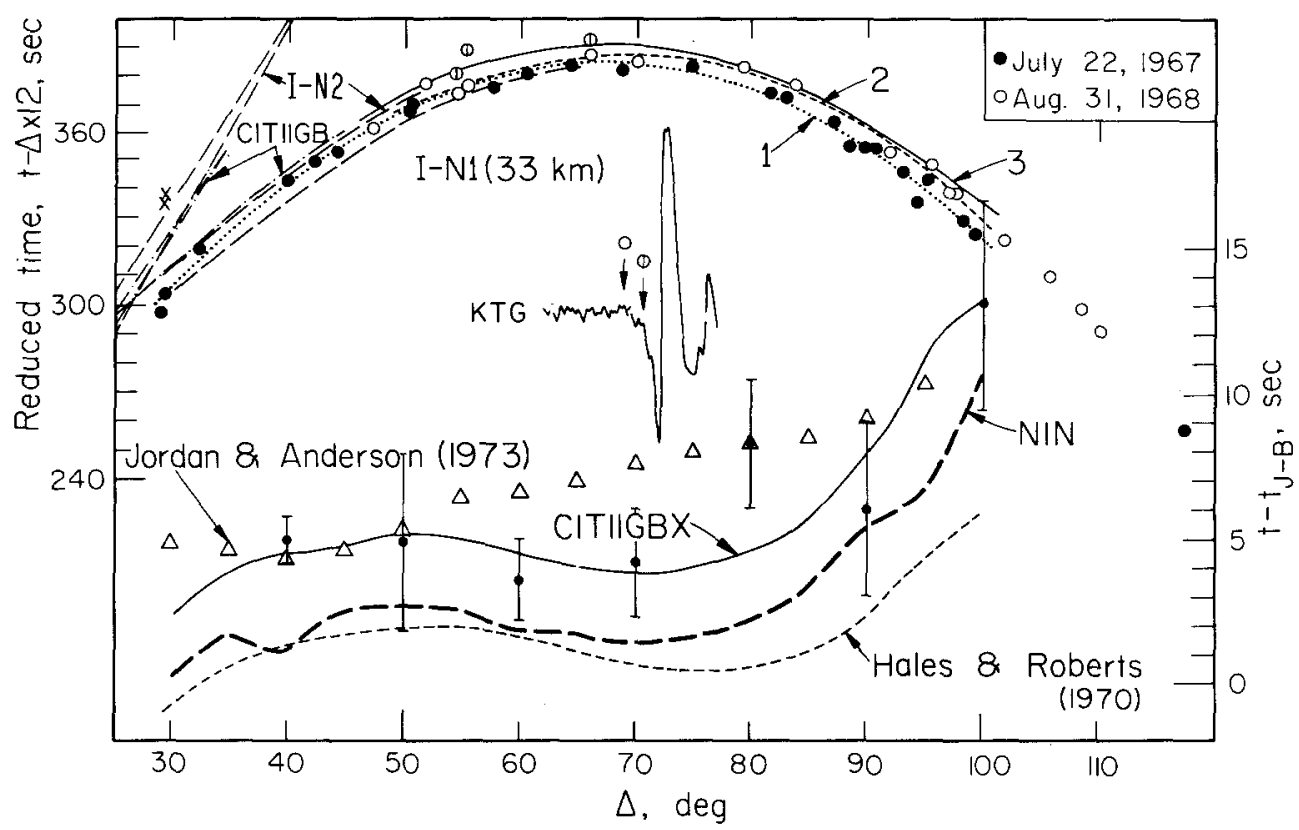

FiG. 2. Observed $S H$ travel-times on a reduced scale. Curves 1 and 2 are the cubic fits to the observations of earthquakes 1 and 2, respectively. Curve 3 is the cubic fit to the combined data after focal depth adjustment to surface focus was made (see Table 2). In the lower part, the observed residuals with respect to $J-B$ Tables are shown. The solid curve is determined from curve 3 . The long-dash curve is obtained from base-line adjustment to IN-2 of the data of individual earthquakes at $\Delta=40^{\circ}$. The solid circles are the $10^{\circ}$ averages of the data to which curve 3 is fitted, within their standard deviations.

It was found that the computed times for CIT IIGBX fit the observed times, curve 3, to within $\pm 0.3 \mathrm{sec}$ at epicentral distances of $35^{\circ}$ to $45^{\circ}$, and therefore, it was chosen as one of two possible upper mantle structures in the determination of lower mantle shear velocities.

In the lower part of Figure 2, the residual times from $J$ - $B$ Tables of curve 3, as shown by the heavy solid curve, are compared with those given by Hales and Roberts (1970) and Jordan and Anderson (1973). The discrete points shown by the barred solid circles are the $10^{\circ}$ means and their standard deviation, computed from the last column of Table 2. The CIT11GBX residuals shown in Figure 2 agree reasonably well with the observations 
made by Lehmann (1964), Cleary (1969), Bolt et al. (1970), and by Doyle and Hales (1967) when they used Kogan's (1960) observation near $42^{\circ}$ distance for base-line adjustment.

Hales and Roberts' (1970) curve includes a base-line adjustment to satisfy the data of Ibrahim and Nuttli (1967) near $\Delta=30^{\circ}$. Adjusting the base line of the observed travel times of earthquakes 1 and 2 individually to Nuttli's (1969) IN2 model near angular distance of $40^{\circ}$ (where $d t / d \Delta$ 's match), and combining the adjusted times, we come up with a travel-time curve (NIN) of which the residuals are also shown in Figure 2. It is interesting to note the similarity between the shapes of these two curves, both having a broad maximum near $50^{\circ}$ and a minimum near $70^{\circ}$. The differences are smaller than 1 sec up to $70^{\circ}$.

\section{SHEAR-WAVE Velocities}

The observed travel times, curve 3 and NIN, were inverted to mantle shear-wave velocity structures using the standard Wiechert-Herglotz inversion method. The Earth was stripped of the $830-\mathrm{km}$ thick uppermost layer with CIT11GBX structure, and appropriate adjustment was made in curve 3 . For the inversion of NIN, the Earth was stripped of an $885-\mathrm{km}$ thick section of the crust and upper mantle taken from the top of IN2 model (Nuttli, 1969). The structures resulting from the inversion processes are

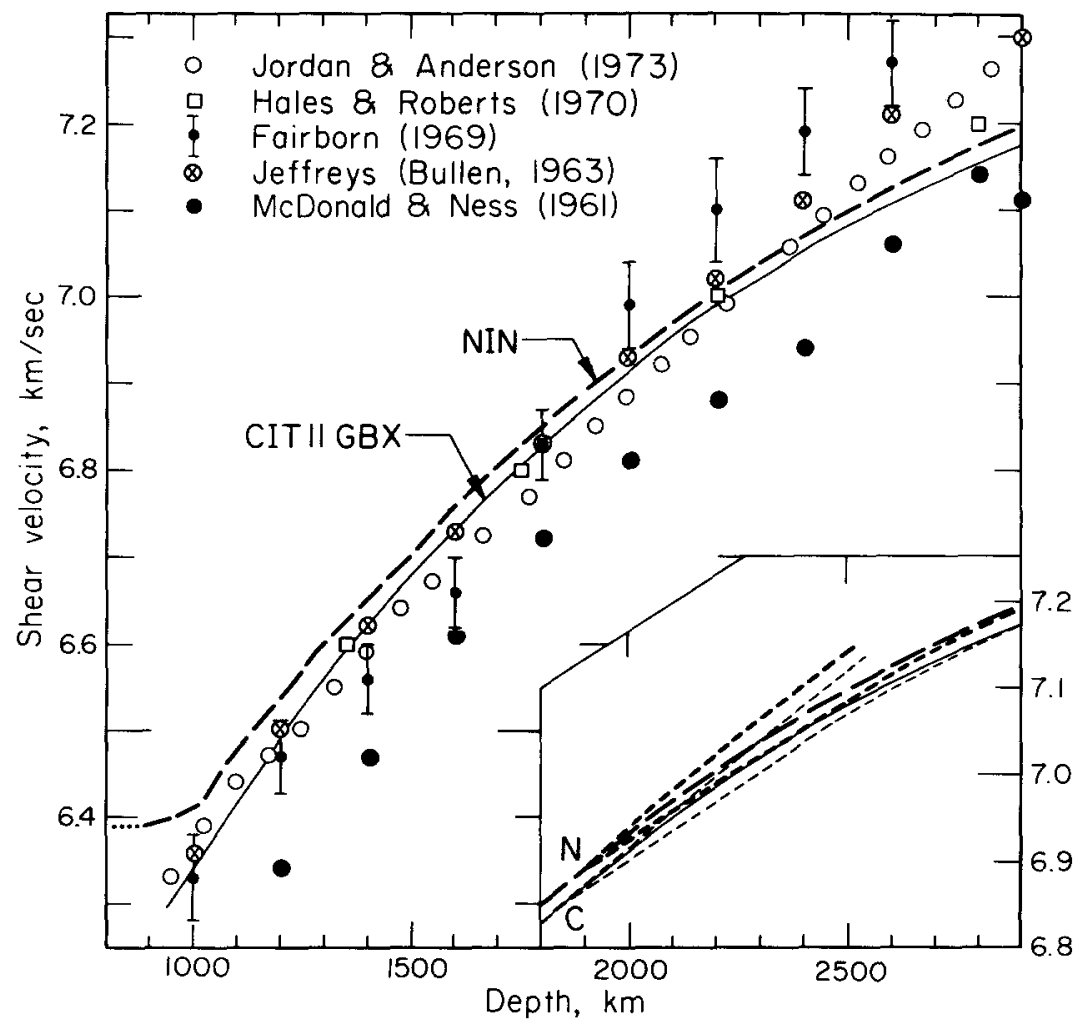

FIG. 3. Shear-wave velocity structures obtained from curve 3 (CIT11GBX) and from NIN travel times. The insert shows the range of variation of shear-wave velocity in the lower mantle below $1,800 \mathrm{~km}$ for the two profiles, determined from the spread of the travel times beyond $70^{\circ}$ angular distance. The upper bound is derived from the travel times along the rays bottoming in the vicinity of Iceland. 
tabulated in Table 3 and are compared with the corresponding structures given by Jeffreys (Bullen 1963), Fairborn (1969), Hales and Roberts (1970), and Jordan and Anderson (1973) in Figure 3. It is observed that, in the lowermost $800 \mathrm{~km}$ of the mantle, the structures derived from the combined data CIT11GBX and NIN give shear-wave velocities smaller than most other estimates in which no allowance is made for possible $P$ to $S$ conversion. It is perhaps appropriate to point out that MacDonald and Ness

TABLE 3

Mantle Shear Veloctty Structure

\begin{tabular}{|c|c|c|c|c|c|c|}
\hline \multirow{2}{*}{$\underset{(\mathrm{km})}{\text { Depth }}$} & \multicolumn{3}{|c|}{$\mathrm{NIN}(\mathrm{km} / \mathrm{sec})$} & \multicolumn{3}{|c|}{$\mathrm{ClT} 11 \mathrm{GBX}(\mathrm{km} / \mathrm{sec})$} \\
\hline & N. Pole & Average & Iceland & N. Pole & Average & Iceland \\
\hline 0.0 & & 3.50 & & & 3.53 & \\
\hline 22.0 & & 3.50 & & & 3.53 & \\
\hline 22.0 & & 3.50 & & & 3.80 & \\
\hline 36.0 & & 3.50 & & & 3.83 & \\
\hline 36.0 & & 4.60 & & & 4.60 & \\
\hline 80.0 & & & & & 4.40 & \\
\hline 147.0 & & 4.60 & & & & \\
\hline 150.0 & & & & & 4.40 & \\
\hline 170.0 & & & & & 4.50 & \\
\hline 181.0 & & 4.00 ， & & & & \\
\hline 201.0 & & 4.60 & & & & \\
\hline 221.0 & & 4.65 & & & & \\
\hline 350.0 & & & & & 4.55 & \\
\hline 376.0 & & 4.65 & & & & \\
\hline 391.0 & & 5.10 & & & & \\
\hline 400.0 & & & & & 5.00 & \\
\hline 460.0 & & & & & 5.40 & \\
\hline 471.0 & & 5.37 & & & & \\
\hline 650.0 & & & & & 5.50 & \\
\hline 726.0 & & 5.37 & & & & \\
\hline 730.0 & & & & & 6.00 & \\
\hline 750.0 & & & & & 6.20 & \\
\hline 761.0 & & 6.38 & & & & \\
\hline 840.0 & & & & & 6.23 & \\
\hline 885.0 & & 6.38 & & & & \\
\hline 1000.0 & & 6.42 & & & 6.34 & \\
\hline 1200.0 & & 6.54 & & & 6.49 & \\
\hline 1400.0 & & 6.65 & & & 6.61 & \\
\hline 1600.0 & & 6.76 & & & 6.73 & \\
\hline 1800.0 & 6.85 & 6.85 & 6.85 & 6.83 & 6.83 & 6.83 \\
\hline 2000.0 & 6.92 & 6.93 & 6.94 & 6.89 & 6.91 & 6.91 \\
\hline 2200.0 & 6.99 & 7.01 & 7.02 & 6.97 & 6.99 & 7.00 \\
\hline 2400.0 & 7.06 & 7.07 & 7.10 & 7.03 & 7.05 & 7.08 \\
\hline 2600.0 & 7.12 & 7.13 & 7.18 & 7.10 & 7.11 & 7.16 \\
\hline 2800.0 & 7.17 & 7.17 & & 7.15 & 7.15 & \\
\hline 2886.0 & 7.19 & 7.19 & & 7.17 & 7.17 & \\
\hline
\end{tabular}

(1961) suggested, based on observed periods of free oscillations, a reduction in the shearwave velocities in the lower mantle. Their preferred model, a modification of the Gutenberg shear-velocity structure, generally gives lower $S$ velocities by more than $0.1 \mathrm{~km} / \mathrm{sec}$ than CIT11GBX in the range of our interest. Near the core-mantle boundary, however, the two models approach to within $0.03 \mathrm{~km} / \mathrm{sec}$ of each other. 
In the insert of Figure 3, the range of variation of shear-wave velocities for the two profiles through the North Pole and near Iceland, inferred from the observed traveltime differences, are also shown for CIT11GBX and NIN. To obtain these regional variations, the observed travel-time differences of the two earthquakes (Figure 2) up to the angular distances of $70^{\circ}$ were assumed to be insignificant. After the depth correction is applied, the difference in the cubic curves 1 and 2 are less than $1 \mathrm{sec}$ at distances less than $72^{\circ}$. The penetration depth of the ray which emerges at $70^{\circ}$ is about $1,800 \mathrm{~km}$. The observed differences in the travel times beyond $70^{\circ}$ are, therefore, assigned to structural differences below $1,800 \mathrm{~km}$. As may be expected from the distribution of the observed points beyond $90^{\circ}$ distance (Figure 2), the structure of the lowermost $300 \mathrm{~km}$ of the mantle is more strongly influenced by the data of earthquake (2), for which the ray paths graze the core beneath the North Pole. This is evident in the proximity of the average models with those of the polar region at this depth range. It is clear that the lateral variation of the shear-wave velocity near the core boundary for these two regions, obtained from $L P$ travel-time data, may amount to as much as $0.1 \mathrm{~km} / \mathrm{sec}$ or over 1 per cent.

Bolt et al. (1970) interpreteted the observed 12-sec delay, nearly $15 \mathrm{sec}$ after depth correction is made, of $S H$ arrivals relative to $J-B$ Tables to have been caused by a lowvelocity channel at the base of the mantle. Although they considered the possibility of the integrated effect of lower velocities throughout much of the mantle, relative to Jeffreys model, using Fairborn's (1969) estimate of $7.27 \mathrm{~km} / \mathrm{sec}$ for the $S$ velocity at a depth of $2,600 \mathrm{~km}$, they suggested a decrease of about 3 per cent for shear-wave velocity in the lowest $300 \mathrm{~km}$ of the mantle. It now appears that Fairborn's mean estimates of $S$ velocities near the base of the mantle is much higher than most of the standard solutions.

In the present analysis, no allowance is made for possible decrease of velocity with depth. However, it is noted that the observed delays relative to $J$ - $B$ tables for the $S H$ arrivals of earthquake 2 begin to build up from $\Delta=70^{\circ}$. This observation favors the alternative explanation that the delay may be caused by the accumulated effect of slower shear-wave velocities in the lowest $1,000 \mathrm{~km}$ of the mantle. The corresponding delay for earthquake 1 is nearly half of that observed from the data of earthquake 2. Also, as can be seen from the record section of this earthquake at angular distances of $85^{\circ}$ to $95^{\circ}$ (Figure 4), the lower mantle shear-wave velocity in the Iceland region shows a rapid increase near a depth of $2,700 \mathrm{~km}$. Whether below this depth there is another increase in velocity as Mitchell and Helmberger (1973) suggest, or a slow decrease, in partial accordance with the suggestions of Cleary (1969) and Bolt et al. (1970), is difficult to establish. Two points, however, clearly emerge from our analysis: first, the existence of lateral heterogeneities in the lower mantle shear-wave velocities amounting to regional variations of nearly $0.1 \mathrm{~km} / \mathrm{sec}$ are clearly demonstrated. Second, the present data would not accommodate a pronounced worldwide low-velocity channel around the core.

The resolution of long-period $S H$ signals recorded at distances larger than $95^{\circ}$ of earthquake 1, being few and weak, is not sufficient for a detailed analysis of the structure below $2,650 \mathrm{~km}$. The short-period seismograms of this earthquake recorded at stations from $83.3^{\circ}$ to $95.05^{\circ}$ distance and $325.9^{\circ}$ to $336.5^{\circ}$ azimuth were examined for this purpose. ALQ, BOZ, DUG, and GOL are the only relevant WWSS observatories with very high magnifications $(400 \mathrm{~K}$ at $1 \mathrm{~Hz})$. SES is a station of the Canadian network with magnifications at $1 \mathrm{~Hz}$ of $41 \mathrm{~K}$ and $44 \mathrm{~K}$ for N-S and E-W components, respectively. The horizontal seismograms of these five stations were digitized and rotated. The resulting transverse and longitudinal components are reproduced in Figure 4. Several features of the record sections, such as the $S-S K S$ crossover at $83^{\circ}$ to $84^{\circ}$, possible triplication of $S$ at $\mathrm{BOZ}$ and DUG, and a change of gradient of $S$ travel time near $90^{\circ}$ 
are of interest. Assuming the CIT11GBX solution for the Iceland region to hold down to a depth of $2,650 \mathrm{~km}$, several models were tried to determine whether these features may simultaneously be synthesized. The travel times of two such models for a focal depth of $21 \mathrm{~km}$ are superimposed on the $S, S c S$, and $S K S$ observations in Figure 4. Both of these models have an abrupt jump of velocity to $7.35 \mathrm{~km} / \mathrm{sec}$ at $h=2,680 \mathrm{~km}$, as shown in the insert. The solid curve retains this high velocity down to the core boundary. The dashed curve resulted when the velocity decreases gradually to $7.30 \mathrm{~km} / \mathrm{sec}$ (predicted by Jeffreys model) at that boundary. The main differences in the travel-time

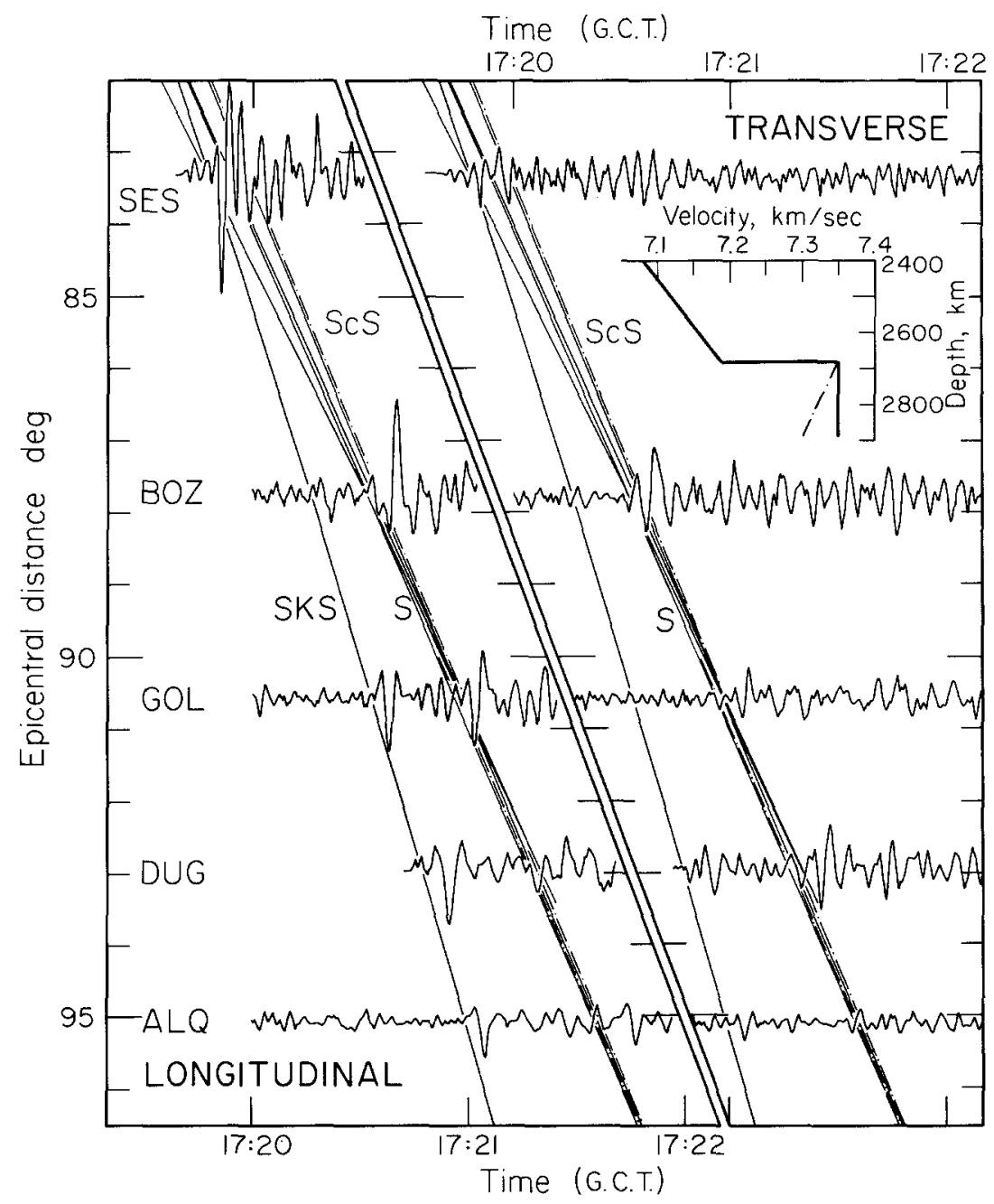

Fig. 4. Rotated short-period seismograms of earthquake 1. The travel-time curves are computed from the upper branch of the CIT11GBX structure with modifications for $21-\mathrm{km}$ focal depth as shown in the insert.

curves of these models are the difference in the shadow boundary (about $100^{\circ}$ for constant-velocity layer versus $103^{\circ}$ for the layer with negative-velocity gradient) and the slope of the travel-time curve beyond $90^{\circ}$. The only stations with usable short-period records at distances larger than $90^{\circ}$, and in the azimuth range of interest, are DUG and ALQ. $S$ arrivals at these stations appear to be more in favor of a positive than a negative 
gradient above the core boundary. Whether or not this gradient has been affected by lateral variations is difficult to ascertain. In the computation of $S K S$ travel times, the compressional velocities in the outer core are taken from Hales and Roberts (1971), and a core radius of $3,485 \mathrm{~km}$ is assumed (Jordan and Anderson, 1973).

\section{CONCLUSIONS}

Comparison of $\mathrm{SH}$ travel times of two shallow earthquakes occurring in similar hypocentral environments (shallow continental sources associated with predominantly strike-dip surface faulting) and recorded in practically the same region (tectonically active region of western North America) indicate differences in the shear-wave velocity structures of the deep mantle. The inferred difference for the two regions sampled by the data, i.e., the North Pole and Iceland regions, amounts nearly to 1 per cent at $2,500-\mathrm{km}$ depth. Implied lateral heterogeneity at the base of the mantle for shear velocity, as well as compressional velocity, may be, in part, responsible for inconsistent observations of spectral phase and amplitude characteristics of $P c P$ such as those reported by Buchbinder (1968), Kogan (1972), and Berzon et al. (1972).

\section{ACKNOWLEDGMENTS}

Professors Don L. Anderson and Donald V. Helmberger kindly read the manuscript and made valuable suggestions. Some of the computer programs used in this study were originally written by Drs. $\mathrm{H}$. Kanamori, J. Whitcomb, and B. Julian. Graphs were prepared by Mr. Laszlo Lenches. This research was supported by the Advanced Research Projects Agency of the Department of Defense and was monitored by the Air Force Office of Scientific Research under Contract F44620-72-C-0078.

\section{REFERENCES}

Ambraseys, N. N. and J. S. Tchalenko (1969). The Dasht-e Bayaz (Iran) earthquake of August 31, 1968: a field report, Bull. Seism. Soc. Am. 59, 1751-1792.

Ambraseys, N. N. and A. Zatopeck (1969). The Murdurnu Valley, West Anatolia, Turkey earthquake of July 22, 1967, Bull. Seism. Soc. Am. 59, 521-589.

Băth, M, and R. Stefansson (1966). $S-P$ conversion at the base of the crust, Ann. Geofis. (Rome) 19, 119-130.

Berzon, I. S., S. D. Kogan, and I. P. Passechnik (1972). The character of the mantle-core boundary from observations of $P c P$ waves, Earth Planet. Sci. Letters 16, 166-170.

Bolt, B. A., M. Niazi, and M. R. Sommerville (1970). Diffracted $S c S$ and the shear velocity at the core boundary, Geophys. J. 19, 299-305.

Buchbinder, G. G. R. (1968). Properties of the core-mantle boundary and observations of PcP, J. Geophys. Res, 73, 5901-5923.

Bullen, K. E. (1973). The ellipticity correction to travel times of $P$ and $S$ earthquake waves, Monthly Notices Roy. Astron. Soc., Geophys. Suppl. 4, 143-157.

Bullen, K. E. (1963). An Introduction to the Theory of Seismology, 3rd. ed. Cambridge University Press, p. 223.

Chinnery, M. A. and M. N. Toksöz (1967). P wave velocities in the mantle below $700 \mathrm{~km}$, Bull. Seism. Soc. Am. 57, 199-226.

Cleary, J. (1969). The $S$ velocity at the core-mantle boundary, from observations of diffracted $S, B u l l$. Seism. Soc. Am. 59, 1399-1405.

Cook, K. L., S. T. Algermissen, and J. L. Costain (1962). The status of $P S$ converted waves in crustal studies, J. Geophys. Res. 67, 4769-4778.

Corbishley, D. J. (1970). Multiple array measurements of the $P$-wave travel-time derivative, Geophys. $J$. 19, 1-14.

Davies, D. and R. M. Sheppard (1972) Lateral heterogeneity in the Earth's mantle, Nature 239, 318-323.

Doyle, H. A. and A. L. Hales (1967). An analysis of the travel time of $S$ waves to North American stations, in the distance range $28^{\circ}$ to $82^{\circ}$, Bull. Seism. Soc. Am. 57, 761-771.

Enayatollah, M. A. (1972). Continental array measurements of $P$-wave velocities in the mantle, Pure Appl. Geophys. (Milan) 94, 2, 136-147.

Fairborn, J. W. (1969). Shear-wave velocities in the lower mantle, Bull. Seism. Soc. Am. 59, 1983-1999.

Hales, A. L., J. R. Cleary, and J. L. Roberts (1968). Velocity distribution in the lower mantle, Bull. Seism. Soc. Am. 58, 1975-1989. 
Hales, A. L. and J. L. Roberts (1970). Shear velocities in the lower mantle and the radius of the core, Bull. Seism. Soc. Am. 60, 1427-1436.

Hales, A. L. and J. L. Roberts, (1971) The velocities in the outer core, Bull. Seism. Soc. Am. 61, 1051-1059.

Ibrahim, A. K. and O. W. Nuttli (1967). Travel-time curves and upper mantle structure from long-period S waves, Bull. Seism. Soc. Am. 57, 1063-1092.

Johnson, L. R. (1967). Array measurements of $P$ velocities in the upper mantle, J. Geophys. Res. 72, 6309-6325.

Johnson, L. R. (1969), Array measurements of $P$ velocities in the lower mantle, Bull. Seism. Soc. Am. 59, 973-1008.

Jordan, T. H. and D. L. Anderson (1973). Earth structure from free oscillation and travel time, Geophys. $J$. (in press).

Julian, B. R, and D. L. Anderson (1968). Travel times, apparent velocities, and amplitudes of body waves, Bull. Seism. Soc. Am. 58, 339-366.

Julian, B. R. and M. K. Sengupta (1973). Seismic travel time evidence for lateral inhomogeneity in the deep mantle, Nature 242, 443-447.

Kanamori, H. (1967). Upper mantle structures from apparent velocities of $P$ waves recorded at Wakayama Micro-earthquakes Observatory, Bull. Earthquake Res. Inst., Tokyo Univ. 45, 657-678.

Kanasewich, E. R., R. M. Ellis, C. H. Chapman, and P. R. Culowski (1973). Seismic array evidence of a core boundary source for the Hawaiian linear volcanic chain, J. Geophys. Res. 78, 1361-1371.

Kogan, S. D. (1960). Travel times of longitudinal and transverse waves calculated from data on underground explosions made in the region of the Marshall Islands, Bull. Acad. Sci. USSR, Geophys. Ser. (English Transl.), 3, 246-253.

Kogan, S. D. (1972) A study of the dynamics of a longitudinal wave reflected from the Earth's core, Bull. Acad. Sci. USSR, Phys. Solid Earth, (English Trans.) 339-349.

Kovach, R. L. and R. Robinson (1969). Upper mantle structure in the Basin and Range Province, western North America, from the apparent velocities of $S$ waves, Bull. Seism. Soc. Am. 59, 1653.

Lehmann, I. (1964). The Hindu Kush earthquake of March 4, 1949, as recorded in Europe, Bull. Seism. Soc. Am. 54, 1915-1925.

Lomnitz, C. (1971). Travel-times errors in the laterally inhomogeneous $\mid$ Earth $\mid$ Bull. $\mid$ Seism. $\mid$ Soc. Am. $\mid \mathbf{6 1}$, $1639-1654$.

MacDonald, G. J. F. and N. F. Ness (1961). A study of the free oscillations of the Earth, J. Geophys. Res. 66, 1865-1911.

McKenzie, D. (1972). Active tectonics of Mediterranean region, Geophys.J. 30, 109-185.

Mitchell, B. J. and D. V. Helmberger (1973). Shear velocities at the base of the mantle from observations of $S$ and $S c S$, J. Geophys. Res. (in press).

Niazi, M. (1969). Source dynamics of the Dasht-e Bayaz earthquake of August 31, 1968, Bull. Seism. Soc, Am. 59, 1843-1861.

Niazi, M. and D. L. Anderson (1965). Upper mantie structure of western North America from apparent velocities of $P$ waves, $J$. Geophys. Res. 70, 4633-4640.

Nuttli, O. W. (1969). Travel times and amplitudes of $S$ waves from nuclear explosions in Nevada, Bull. Seism. Soc. Am. 59, 385-398.

Pachadzhanova, G. N. (1962). Study of transformed waves of SP type during deep Afghan earthquakes, Tr. Inst. Astrofiz. Stalinabad (in Russian) 10, 108-124.

Phinney, R. A. and S. S. Alexander (1969). The effect of velocity gradient at the base of the mantle on diffracted $P$ waves in the shadow, J. Geophys. Res. 74, 4967-4971.

Robinson, R. and R. L. Kovach (1972). Shear-wave velocities in the Earth's mantle, Phys. Earth and Planet. Int. 5, 30-44.

Smith, W. D. (1970). S to P conversion as an aid to crustal studies, Geophys. J. 19, 513-519.

Toksöz, M. N., M. A. Chinnery, and D. L. Anderson (1967). Inhomogeneities in the Earth's mantle, Geophys. J. 13, 31-59.

Vinnik, L. P., A. A. Lukk, and A. V. Nikolaev (1972). Inhomogeneities in the lower mantle, Phys. Earth Planet. Int. 5, 328-331.

Selsmological Laboratory

California Institute of Technology

Pasadena, California 91109

Contribution No. 2347, Division of

Geological and Planetary Sciences

Manuscript received May 7, 1973 